\title{
Diagnóstico na Infância: Quais as Implicações Possíveis?
}

\author{
Heloisa Cardoso da Silva \\ Universidade do Vale do Rio dos Sinos (UNISINOS) \\ Mercês Sant'Anna Ghazzi \\ Faculdade São Francisco de Assis \\ Centro Lydia Coriat Porto Alegre
}

\begin{abstract}
RESUMO
Este artigo objetivou abordar as especificidades do processo diagnóstico nas psicopatologias na infância a partir de uma revisão da literatura. Num primeiro momento, realizou-se uma fundamentação teórica acerca de como a psicanálise concebe o diagnóstico, contrapondo com a perspectiva médica. Posteriormente, refletiu-se sobre como pensar esse processo na infância, considerando suas particularidades. Por fim, discutiram-se as repercussões do ato diagnóstico nesse período tão peculiar, tendo como inspiração recortes da prática em psicologia clínica e escolar, articulando-os com os achados teóricos. Enfim, discutiu-se sobre a excessiva prescrição medicamentosa percebida na atualidade, como também sobre os efeitos possíveis que podem surgir nos espaços por onde a criança circula: seu meio familiar, escolar e social.
\end{abstract}

Palavras-chave: Diagnóstico; infância; psicanálise.

\section{ABSTRACT \\ Diagnosis of childhood: what are the possible implications?}

This article aimed to address the specificities of the diagnostic process in psychopathology in childhood from a literature review. At first, there was a theoretical basis on how psychoanalysis conceives diagnosis, contrasting with the medical perspective. Subsequently, reflected on how this thinking process in childhood, considering its particularities. Finally, were discussed the repercussions of the diagnostic act so peculiar in that period, taking as inspiration clippings practice in clinical psychology and school linking them with the theoretical findings. Anyway, it was discussed about the excessive prescriptions perceived today, but also about the possible effects that may arise in the spaces where the child circulates: their family environment, school and social.

Keywords: Diagnosis; childhood; psychoanalysis.

Este escrito é resultado de algumas reflexões suscitadas, sobretudo, a partir da prática clínica com crianças e adolescentes num serviço público que oferece atendimento psicológico e assessoria a escolas de um município do Rio Grande do Sul. A experiência nesse centro vem revelando uma situação que demanda atenção: muitas crianças vêm para atendimento carregando consigo um diagnóstico já estabelecido, realizado, em sua maioria, por profissionais da área médica, principalmente psiquiatras e neurologistas.

Ao mesmo tempo, além dessa questão do diagnóstico, é possível perceber outro ponto que igualmente requer um olhar crítico: a prescrição excessiva de medicação nessa fase constituinte da vida do sujeito, como se esse recurso fosse o único ou o principal na condução terapêutica das psicopatologias nesse período. A respeito disso, pode-se citar como exemplo o uso do Cloridrato de Metilfenidato, conhecido popularmente como Ritalina, comumente prescrita a crianças diagnosticadas com transtorno de déficit de atenção e hiperatividade (TDAH). De acordo com a Agência Nacional de Vigilância Sanitária (ANVISA) (Brasil, 2012), esse medicamento teve uma elevação eloquente de consumo de $75 \%$ entre crianças de seis a 16 anos, dentre 2009 e 2011, e a explicação dos psiquiatras para esse crescimento se relaciona ao diagnóstico do TDAH estar mais apurado.

Isso vai ao encontro do que diz Fiore (2005), de que cada vez mais se eleva o número de crianças diagnosticadas com TDAH. Desse modo, pode-se pensar que esse alastramento significativo contribui expressivamente com a medicalização infantil. Jerusalinsky (2011) questiona o porquê de haver esse crescimento da prescrição de Ritalina, uma vez que ela foi lançada com a 
promessa de curar o TDAH. Assim, não seria esse remédio uma das razões para tal propagação?

Dessa forma, atualmente o TDAH é tratado, sobretudo pelos meios de comunicação, praticamente como uma epidemia, e os sintomas que o caracterizam, presentes no Manual Diagnóstico e Estatístico de Transtornos Mentais - DSM-5 (American Psychiatric Association [APA], 2014) e na Classificação de Transtornos Mentais e de Comportamento da CID-10 (Organização Mundial da Saúde [OMS], 1993), como também o uso da Ritalina como caminho para o tratamento, são difundidos de forma simplista e reducionista. Inclusive, associa-se a terapia cognitivo-comportamental (TCC) como a única forma de tratamento possível (Guarido, 2007).

Todas essas questões perpassam a escola, local onde, amiúde, aquilo que a criança está expressando há tempos - seja um sintoma ou uma psicopatologia - é detectado pela primeira vez. Dessa maneira, a escola vê-se diante de algo desafiador, do qual deve dar conta, e através dos encaminhamentos e das assessorias prestadas, percebe-se que, por vezes, o discurso escolar sustenta esses diagnósticos que são realizados, passando a defender e exigir da família da criança que ela seja medicada.

Nesse sentido, discutir essa problemática torna-se fundamental no contexto atual, uma vez que, em maio de 2013, foi lançada pela Associação Americana de Psicologia (APA) a quinta edição do Manual Diagnóstico e Estatístico de Transtornos Mentais (DSM-V). A publicação desse manual, que é conhecido como a Bíblia da Psiquiatria, está despertando muito debate no meio psi, e as críticas são dirigidas não apenas às mudanças ocorridas na concepção e na criação de novas psicopatologias, mas também às possíveis consequências dessa prática da patologização.

Diferentemente do ponto de vista médico, a psicanálise apresenta um caminho diferente de compreensão do processo diagnóstico na infância. Uma criança é vista como um sujeito em constituição psíquica, a partir da sua singularidade e história de vida (Bernardino, 2006). Logo, ao mesmo tempo em que ele é um norte na condução do tratamento clínico, o seu diagnóstico não pode ser concebido como inflexível e fechado (Adelino, 2010).

Assim, esse trabalho visou abordar as especificidades do processo diagnóstico de psicopatologias na atualidade, sobretudo na infância, problematizando-o a partir do referencial psicanalítico e contrapondo-o com o referencial médico. Ademais, refletiu-se acerca da prescrição medicamentosa na infância e discutiram-se possíveis implicações da atual prática imoderada de diagnósticos e medicalização nesse momento constituinte e crucial. Para isso, alguns interrogantes nortearam esse escrito: a serviço de que está essa crescente medicalização na infância? Que efeitos possíveis pode haver a esse sujeito em constituição, que é diagnosticado e medicado precocemente? Que repercussões essas questões podem surgir nos espaços por onde essa criança circula, isto é, meio familiar, escolar e social?

Enfim, são interrogações importantes de serem feitas, sendo indispensável problematizá-las "no contexto de uma sociedade que busca a eficiência a todo custo, sociedade das urgências, essencialmente hiperativa e que se utiliza de rótulos como sofisticados métodos de controle da subjetividade" (Fiore, 2005, p. 366). Isto é, faz-se necessária uma análise crítica disso que envolve a infância na contemporaneidade. Para isso, realizou-se uma revisão da literatura sobre a temática nas bases de dados Scielo, Portal da CAPES e BVS Psicologia Brasil, visando trabalhos com fundamentação psicanalítica, sem critério pré-estabelecido quanto ao ano de publicação, buscando-se traçar uma discussão inspirada em recortes da prática clínica e institucional.

\section{O DIAGNÓSTICO NA INFÂNCIA: DIFERENTES CON- CEPÇÕES E SEUS EFEITOS}

\section{0 que é diagnosticar?}

Primeiramente, considerando-se a temática proposta para debate, faz-se pertinente partir de duas interrogações importantes: 1) o que é diagnosticar? 2) o que é diagnóstico? Etimologicamente, a palavra diagnóstico advém do grego "Diagignóskein", que representa distinguir, discernir, diferenciar; constituída pelos prefixos "dia" (através) e "gignóskein" (conhecimento), indicando que diagnóstico significa "através do conhecimento" (Consultório Etimológico, 2013). Ademais, de acordo com o dicionário, diagnosticar é "fazer o diagnóstico", (...) "dar ou estabelecer como diagnóstico", ao passo que diagnóstico é "respeitante a diagnose", (...) "conhecimento ou determinação duma doença pelo(s) sintoma(s), sinal ou sinais e/ou mediante exames diversos", (...) "o conjunto de dados em que se baseia essa determinação" (Ferreira, 2004, p. 671).

Diante disso, percebe-se que tais definições apontam para o sentido genérico do que é um diagnóstico, contudo não dão conta quando se trata da subjetividade de um sujeito. Dessa maneira, considera-se relevante tra- 
çar uma diferenciação de como a psicanálise e a psiquiatria concebem o diagnóstico em suas práticas.

De forma geral, a psicanálise compreende que se faz necessário o estabelecimento de um diagnóstico com o intuito de determinar a orientação quanto à condução da cura. Desde os seus primeiros trabalhos, Freud (1895/2006), em seu texto Psicoterapia da Histeria, indicou que no tratamento psicanalítico institui-se inicialmente um diagnóstico, enquanto que a sua permanência se confirmará apenas após um tempo.

Para a realização diagnóstica, a técnica investigativa que o terapeuta dispõe é a sua escuta. Dessa forma, o diagnóstico fundamenta-se a partir do discurso do paciente, ao mesmo tempo em que se apoia na subjetividade do profissional que o escuta (Dor, 1994.). Como afirma Petri (2008), “o compromisso da psicanálise é com o sujeito, em toda a sua singularidade, e não com um sistema classificatório" (p. 95-96).

As respostas às indagações desencadeadas diante de um paciente são buscadas em sua fala. Se a fala do paciente é ausente na prática psiquiátrica, na clínica psicanalítica tem um papel protagonista, e o paciente é convidado a comparecer de viva voz, ao mesmo tempo em que se conduz a entrevista de modo que se faça comparecer o sujeito (Figueiredo \& Tenório, 2002).

Dessa forma, a psicanálise sustenta-se no método estruturalista quanto à sua forma de diagnosticar, e isso implica um caminho peculiar: o saber sobre o paciente é articulado no decorrer de uma relação terapêutica, em que as questões transferenciais são consideradas e enfatizadas. Assim, o terapeuta dispõe de sua escuta para acolher e compreender o discurso do paciente, e fará uma avaliação subjetiva daquilo que é seu campo de investigação: a estrutura do sujeito. Quando se trata de fenômenos psíquicos, a lógica hipotético-dedutiva, fundamentada no raciocínio cartesiano, não consegue dar conta de "explicar e apreender suas dimensões e variabilidades, pois parece não existir inferências estáveis entre as causas psíquicas e os sintomas, na determinação de um diagnóstico" (Romaro, 1999, p. 11).

Assim, para que se chegue à estrutura psíquica do sujeito, é essencial que o diagnóstico e o tratamento sejam concebidos "como elementos indissociáveis e intercambiáveis e a noção de tratamento como um processo em que se define o diagnóstico e não apenas o contrário" (Bursztyn \& Figueiredo, 2012, p. 135). Cabe aqui, então, transmitir o que Jerusalinsky (2011) coloca a respeito da psicopatologia desde o ponto de vista psicanalítico:
De nossa parte, continuamos sustentando uma psicopatologia interpretativa, o que quer dizer não nosográfica, porque não depende de dados, não depende de sintomas, mas de deciframento. Depende de funções que não são funções de eficácias, que são operações de transformação de representações. É por isso que para os humanos os objetos não são objetos, o corpo não é corpo, o cérebro não é meramente o cérebro e os comportamentos não são meramente comportamentos, nem palavras são coleções de fonemas, mas lugares de simbolização (p. 240).

Portanto, o diagnóstico está presente na clínica psicanalítica, no entanto é adotado numa perspectiva distinta da clínica médica, pois o sujeito psicanalítico não é o doente nem a doença, mas sim o sujeito do inconsciente (Gellis, 2000). Assim, para a psicanálise, o diagnóstico não se refere a um saber externo, mas sim à verdade do sujeito (Adelino, 2010).

Por outro lado, para a psiquiatria, o diagnóstico tem uma função distinta da apresentada até então. Dentre outros propósitos, a clínica psiquiátrica visa estabelecer, com base nos sintomas do paciente, as características de sua enfermidade, enquadrando-o numa classificação nosológica. Essa classificação é denominada como analítica, na qual os sintomas são associados entre si e analisados a fim de encontrar algum sentido. Além disso, "nesta clínica, o diagnóstico, diferencial ou não, clínico ou não, precisa estar sempre referido a um discurso preestabelecido, a um saber externo à relação clínico / paciente" (Gellis, 2000, p. 2).

Desse modo, o diagnóstico na psiquiatria tem o papel de esclarecer os processos psicopatológicos invulneráveis à categorização etiológica e nosográfica, que embasam o saber médico acerca do funcionamento orgânico (Vorcaro, 2011). A psiquiatria dispõe a psicopatologia em uma nosografia que se fundamenta em dados, não havendo algo que possa ser desvendado, pois "as coisas revelam o próprio dado, e o dado, reciprocamente, indica a coisa" (Jerusalinsky, 2011, p. 238). Percebe-se, então, que essa é a lógica defendida e propagada pelo DSM-5 (APA, 2014).

A utilidade de um diagnóstico psiquiátrico está atrelada à sua validade e à sua confiabilidade:

A confiabilidade diagnóstica se refere à sua coerência. Ela avalia até que ponto diferentes examinadores fazem o mesmo diagnóstico de um dado paciente, e se esse paciente continua recebendo o mesmo diagnóstico ao longo de sua evolução. A fim de melhorar a validade dos diagnósticos em psiquiatria, as últimas três décadas foram marcadas por enormes esforços de definição diagnóstica em função da presença de sintomas definidos de maneira consensual (Marcelli \& Cohen, 2010, p. 26).

No entendimento de Reis (2000), na psiquiatria, diferentemente da perspectiva psicanalítica, não se considera a possibilidade de uma mudança estrutural. $\mathrm{O}$ 
diagnóstico e o próprio tratamento visam à exclusão da diferença e da individualidade do paciente. Por meio de nomenclaturas reduzidas e peculiares, o médico busca a homogeneidade de sentido e, em algumas entrevistas, institui o caminho diagnóstico investigando a manifestação de sintomas que indiquem a psicopatologia apresentada, baseando-se numa perspectiva fenomenológica, isto é, "nas manifestações que pudessem ser indicadoras de alterações de juízo, pensamento e percepção" (Reis, 2000, p. 5). Assim, ser-lhe-á possível orientar quanto à necessidade e ao tipo de medicação a ser prescrita.

Em função da pretensão de uma precisão científica na incumbência diagnóstica, o caminho psiquiátrico reproduz um "empobrecimento conceitual", além de sujeitar a prática clínica ao diagnóstico, visto que ele é quem detém o saber sobre o paciente (Mendonça, 2013, p. 50). Da mesma maneira "que o diagnóstico empirista desemboca numa nosologia, o positivista transforma isso em classificação" (Saurí, 2001, citado em Mendonça, 2013, p. 51).

Assim, de acordo com Mendonça e Berlinck (2012), os manuais classificatórios de psicopatologias surgiram com o intuito de que houvesse na atuação clínica, dentre os profissionais, uma concordância quanto ao estabelecimento de um diagnóstico, referindo-se à lista de sintomas de cada transtorno. Nesse sentido, os manuais possibilitaram a uniformização da linguagem adotada pelos profissionais de saúde mental para a classificação das perturbações mentais, facilitando a prática clínica (Burkle, 2009). No entanto, segundo Angell (2011), o surgimento desses manuais atendeu também a outro fim: legitimar o uso de psicotrópicos. "Na década de 70, foi preciso facilitar um acordo sobre diagnósticos entre clínicos, cientistas e autoridades reguladoras, dada a necessidade de ligar os pacientes aos novos tratamentos farmacológicos", disse Bernstein, presidente da APA, em um pronunciamento (Angell, 2011, p. 48). Ademais, o DSM, que está dentre um dos mais importantes meios de renda da APA, produz cada vez mais diagnósticos.

Enfim, diante da explanação a respeito do diagnóstico para as perspectivas psicanalítica e psiquiátrica, percebe-se que há diferenças cruciais em suas concepções e práticas. Enquanto a psiquiatria apoia-se em uma compreensão fenomenológica do paciente, a psicanálise busca compreendê-lo a partir da sua estruturação psíquica. Contudo, essas divergências não devem impedir um diálogo entre esses dois saberes, uma vez que a complexidade de um sujeito e de sua subjetividade demanda essa articulação.

\section{Como pensar o diagnóstico na infância?}

Refletir sobre o diagnóstico de psicopatologias infantis implica, antes de tudo, compreender como se constitui psiquicamente uma criança e como se concebe a infância, que é palco desse processo constitutivo. De acordo com Bernardino (2004), esse período “(...) sedia o tempo de passagem do estado de infans - o filhote humano ainda não-falante - ao estatuto de falasser, sujeito falante e desejante" (p. 1, grifos do autor).

Desde o aspecto da maturação, a infância é caracterizada pela intensa plasticidade neuronal, "descoberta da neurobiologia reveladora de que a formação da rede neuronal depende da experiência de vida e que sua plasticidade é suscetível a inscrições dessas experiências" (Ansermet \& Magistretti, 2006, citado em Jerusalinsky et al., 2013, p. 34). No que se refere à constituição psíquica, ela é uma etapa na qual se iniciam as inscrições estruturantes, caracterizando-se pela "permeabilidade a inscrições significantes e pelo polimorfismo das vicissitudes pulsionais" (Jerusalinsky et al., 2013, p. 34).

Assim, para que o psiquismo de um sujeito seja desenvolvido, é fundamental que dois elementos estejam articulados: o primeiro diz respeito ao organismo biológico, sobretudo o sistema nervoso central; o segundo, à existência, na vida dessa criança, de figuras que possam exercer as funções materna e paterna "em suas acepções simbólicas: de introdução na linguagem, a partir da atribuição de um lugar para a criança na família, ou seja, a partir de seu desejo de filho" (Bernardino, 2006 , p. 33, grifos do autor).

Isto é, como apresenta Jerusalinsky (2002):

A estrutura psíquica de um sujeito não está previamente inscrita no bebê por herança filogenética, e sua constituição tampouco ocorre como um simples efeito cronológico. Há um tempo delimitado cronologicamente para que ocorra a inscrição simbólica de certas operações lógicas implicadas na constituição do sujeito psíquico.

(...) para sua constituição psíquica, [a criança] depende de como seja tomado pelo Outro encarnado nesta estrutura simbólica que o antecede. O que implica não só considerar a rede simbólica que o antecede, mas também o desejo de um agente materno que lhe dirija um desejo não anônimo pelo qual possa ser tomado como o bebê de alguém (p. 274).

Dessa forma, nesse tempo primordial, sobretudo nos primeiros anos de vida, diferentemente do adulto, a estrutura psíquica ainda não está decidida e os diversos aspectos instrumentais estão em absoluto processo de 
aquisição (Jerusalinsky, 2002). De acordo com Jerusalinsky e Coriat (1996), os aspectos instrumentais dizem respeito às ferramentas necessárias para que o sujeito produza intercâmbios, possibilitando a construção de mundo e de si mesmo. Esses mecanismos são fundamentais na realização de tudo que o sujeito, a partir do que sua estruturação permite, deseja, e os instrumentos que ele utiliza nesse processo são a psicomotricidade, a linguagem, a aprendizagem, os hábitos de vida diários, o brincar e a socialização.

Com um trabalho teórico-clínico significativo acerca das psicoses não-decididas na infância, Bernardino (2004) sustenta que, nesse período peculiar do ciclo vital, deve-se considerar a estrutura psíquica como nãodecidida, levando-se em conta razões teóricas e clínicas. Em primeiro lugar, por ser o tempo das inscrições constituintes e, ao mesmo tempo, da confirmação desses registros psíquicos, o Nome-do-pai, que é a "instância representativa da falta estrutural do campo simbólico" (p. 2), leva um tempo para se estruturar e se firmar. Assim, são imprescindíveis "os tempos de inscrição, apagamento e interpretação, responsáveis pela inscrição dos significantes primordiais" (p. 2). Portanto, para que se estabeleça a foraclusão do Nome-do-pai e se estruture uma psicose,

(...) é necessário que esta função paterna não se apresente enquanto nome no primeiro momento (tempo do especular e da alienação), nem se apresente como real no segundo momento (tempo edipiano), e ainda assim, até a adolescência (o momento de concluir), é possível que uma latência (o tempo para compreender) - mesmo que longa - represente um tempo de espera de uma sustentação possível desta função no Outro, ou seja, de uma significação fálica (Bernardino, 2004, p. 2).

Além disso, há o segundo ponto, que se refere ao posicionamento do clínico. Atestar a uma criança um diagnóstico de psicose implica firmar "à direção do tratamento condições contrárias às necessárias para o surgimento de um sujeito" (Bernardino, 2004, p. 2), propósito este que é inerente ao trabalho psicanalítico. Se não houver uma aposta por parte do clínico de que possa surgir um sujeito e de que haja possibilidades desejantes no paciente, não será plausível um tratamento analítico.

Nesse sentido, como diz Sibemberg (2013), em razão de que a estrutura psíquica na infância está em constituição, podendo não estar decidida antes da adolescência, ao se instituir um diagnóstico nesse tempo constituinte, essas questões devem ser ponderadas. Então, fechar um diagnóstico precocemente pode não ser "preciso, em ambos os sentidos que a palavra encerra: não é exato e não é necessário" (Coutinho, 2007, p.
106, grifos do autor).

Ao discorrer especificamente sobre a identificação precoce do autismo, Jerusalinsky (2013) questiona se não se trata de uma condição - que pode ter um caráter transitório - ou de uma peculiaridade no processo constituinte da criança. Certamente, considerando todos os aspectos relacionados à estruturação psíquica, esse questionamento pode ser ampliado aos outros quadros psicopatológicos que se expressam na infância.

Da mesma forma, quando uma criança manifesta algum sintoma ou um quadro sintomático, não significa que ele seja um defeito a ser corrigido. Para a psicanálise, a manifestação sintomática é interpretada como uma resposta formulada pelo sujeito frente ao seu conflito psíquico. Também, ao mesmo tempo em que os sintomas devem ser considerados como uma produção significativa do paciente, eles podem ter um caráter efêmero, não devendo, necessariamente, aprisionar o sujeito numa psicopatologia, consolidando nela a sua identidade. Afinal, "diagnóstico não é identidade e tampouco é destino, por isso apostamos em um devir, em uma abertura a inscrições, fundamentalmente na infância" (Jerusalinsky et al., 2013, p. 30).

Nesse contexto, a intervenção precoce configura-se como um trabalho de extrema relevância por levar em conta o sofrimento que emerge prematuramente, porém sem cristalizá-lo em um diagnóstico. Centrar a intervenção na busca e constatação das dificuldades que a criança apresenta significa ignorar por inteiro sua condição de plasticidade e permeabilidade, que lhe é intrínseca. Enfim, uma intervenção precoce "implica considerar, antes de qualquer diagnóstico, a dimensão própria do sujeito na infância" (Jerusalinsky et al., 2013, p. 33).

\section{Quais efeitos podem ser percebidos a partir dos di- agnósticos na infância?}

Considerando os aspectos referentes à infância discutidos até então, de que a criança é um sujeito em constituição, e seu psiquismo ainda está em plena estruturação, é possível inferir que um diagnóstico que lhe é proferido precocemente pode produzir efeitos significativos. Um primeiro ponto diz respeito à prescrição de psicofármacos, muitas vezes indicados por profissionais da medicina - comumente neurologistas e/ou psiquiatras - como o único recurso terapêutico recomendado à criança. Também, pode-se pensar em efeitos no seu próprio processo constitutivo, afetando também aqueles com quem ela convive e de quem de- 
pende: seus pais e seus professores.

A respeito disso, Vorcaro (2011, p. 219) questiona sobre o "efeito bumerangue" que um diagnóstico pode trazer, uma vez que amplia a "ordem de grandeza dos quadros clínicos na medida em que atesta um rigor científico capaz de excluir o saber parental ordinário constitutivo do laço social de qualquer criança". Para a autora, o sistema classificatório que embasa a clínica médica "reduz a criança a uma linhagem médica que lhe é alheia e não contempla seus laços sociais primários" (Vorcaro, 2011, p. 219).

Pode-se pensar essa questão no caso clínico ${ }^{1}$ de uma menina diagnosticada com autismo. Na primeira entrevista, respondendo à pergunta de por que ela foi encaminhada para atendimento, sua mãe refere que a filha é autista desde os seus três meses de vida, pois não fixava seu olhar. Em função desse sinal, os pais procuraram médicos que dissessem a eles o que a menina não conseguiria fazer durante sua vida. Em nenhum momento de sua fala, a mãe chama a filha pelo nome: refere-se a ela simplesmente como autista. E, como aludido, estava no atendimento a fim de lhe fosse ensinado o que a fitha não podia fazer, querendo saber isso a todo custo. Inclusive, em uma pesquisa virtual teria descoberto algo que julgou muito importante: autistas não andam de bicicleta, logo sua filha nunca andaria de bicicleta. Nesse caso, um diagnóstico precoce, em vez de auxiliar numa intervenção que pudesse reverter as dificuldades iniciais na vida da criança, contribuiu para que o olhar materno se fixasse na psicopatologia, nos critérios diagnósticos que lhe foram ensinados nas consultas médicas $\mathrm{e}$, por conseguinte, no que a filha, supostamente, estava impossibilitada de fazer. Assim, aquilo que poderia ser uma condição momentânea e, possivelmente, reversível, cristalizou-se e inviabilizou uma mudança.

Isso vai ao encontro do que apresentam Jerusalinsky et al. (2013), quando defendem a importância da identificação precoce de um sofrimento infantil. Detectar esse sofrimento não requer que o quadro esteja vedado, condizendo com critérios sintomáticos próprios da classificação de uma psicopatologia. Pelo contrário, ao aguardar tal conformidade diagnóstica, perde-se um valioso tempo, em que as dificuldades manifestadas, em função das peculiaridades da infância, podem retroceder e serem revertidas.

No mesmo sentido, é comum escutar pais apresentarem seus filhos como hiperativos, motivo que, com frequência, traz crianças para atendimento psicológico. Porém, não apenas nas entrevistas com pais, mas tam- bém no senso comum, tornou-se habitual denominar crianças consideradas agitadas de hiperativas, havendo inclusive uma suposição de que as crianças de hoje em dia são mais hiperativas.

Essas questões, que são sustentadas e propagadas pela cultura, trazem questionamentos quanto ao saber parental a respeito de seus próprios filhos. Por vezes, como aponta Meira (1998), a referência da criança passa a ser o nome de seu diagnóstico: ser um autista, ser um hiperativo. Essa definição está alheia à linhagem familiar na qual, para sua constituição psíquica, é importante estar referido. Assim, os pais, quando convocados a falar sobre o filho, remetem-se puramente à classificação psicopatológica que lhe foi atribuída.

Não raro, diante de sinais de agitação ou desconcentração do filho, os pais procuram um especialista que lhe nomeiem acerca do que está acontecendo com a criança. Por vezes, a resposta que eles buscam dão um lugar a essa criança: "ela é hiperativa", e não "ela tem hiperatividade". Ou seja, há uma importante diferença entre ser algo ou ter algo. Nesse ponto, cabem algumas interrogações importantes: como os pais acolhem esse diagnóstico conferido ao filho? Há algum efeito no exercício de suas funções materna e paterna a questão do ser algo e/ou do ter algo? O que sabem eles sobre seus filhos para além do diagnóstico que é dado?

Nesse contexto, cabe ressaltar a importância da transmissão simbólica por parte dos pais na constituição de uma criança. Ambos são protagonistas nesse processo, visto que possuem um saber consciente e inconsciente sobre seu filho, o qual sustentará a sua estruturação subjetiva, para além de qualquer quadro psicopatológico. Assim, um trabalho psicanalítico visa desdobrar "este saber em questões, reflexões, preocupações produzidas a partir das experiências cotidianas vividas com o filho", sendo crucial para as transformações que podem decorrer no tratamento (Jerusalinsky et al., 2013, p. 38), tendo em vista que o diagnóstico pode ter "o efeito de 'obstaculizar, nos pais, o exercício das funções parentais"” (Meira, 1998, p. 77).

Além disso, no espaço escolar, essas questões também reverberam. Pode-se perceber isso quando se trata da inclusão escolar, questão esta que atravessa o dia-adia escolar e, por vezes, causa angústia e dúvidas. A legislação sobre educação especial prevê que um aluno, para ser incluído, deve possuir um laudo, com um diagnóstico conforme o manual da CID-10 (OMS, 1993). Contudo, apenas alguns transtornos implicam no direito de haver uma professora auxiliar junto à criança, que 
fique presente em sala de aula, assessorando a professora titular no caso de inclusão. Refere a lei: "considerase público-alvo da educação especial as pessoas com deficiência, com transtornos globais do desenvolvimento e com altas habilidades ou superdotação" (Brasil, 2011, p. 1).

Dessa forma, frequentemente as educadoras solicitam a avaliação psicológica a fim de que o aluno tenha um laudo e, então, possa ter um atendimento especializado. Percebe-se, com frequência, no contato com as professoras que fazem esses pedidos que o diagnóstico de um aluno que lhe traz problemas (seja no transcorrer das aulas, diante da turma ou no fato delas não saberem lidar e se relacionar com o caso, fazendo-as dar-se conta de suas próprias limitações na atuação profissional) imaginariamente as livrará da responsabilidade de se implicar na sua escolarização. Em outras palavras, se há um CID é porque o aluno tem limitações e, portanto, não há muito que se possa fazer por ele.

Nesses casos, o diagnóstico parece trazer um alívio a essas educadoras, pois ajudam a legitimar que a dificuldade no processo de aprendizagem está estritamente relacionada ao aluno, e não também à instituição e, sobretudo, a elas. Acredita-se que, para uma professora, de quem se espera um lugar de saber - que transmite conhecimento e ensina, é muito difícil deparar-se com casos de alunos que apresentam dificuldades e/ou não aprendem. Essa situação se configura como extremamente desafiadora, pois exige que elas possam se interrogar de por que isso acontece, saindo do seu lugar habitual daquela que sabe. Logo, parece que o que está em jogo não é o diagnóstico, mas o que fazer com ele. Afinal, o CID pode ser dado, porém os alunos permanecem na escola, e ela tem que dar conta das questões que isso implica.

Outro aspecto relevante que deve ser mencionado diz respeito à prescrição demasiada de medicação a crianças. Percebe-se que, na atualidade, a Ritalina é um psicofármaco prescrito com frequência àqueles que são diagnosticados com TDAH, e isso pode reverberar no meio familiar e escolar. Não raro, em entrevistas iniciais, escutam-se dos pais referências quanto à pressão e à exigência, por parte da professora do paciente encaminhado, da necessidade de tomar Ritalina para ter um rendimento escolar melhor. Muitas vezes, a criança tem um diagnóstico de TDAH há anos, toma medicação, contudo nunca foi feita uma reavaliação de seu quadro, e as receitas médicas são obtidas por profissionais que não foram os responsáveis pelo diagnóstico atribuído, nem pela prescrição inicial do tratamento medicamentoso, tampouco acompanharam a criança. Assim, às vezes há essa pressão escolar pela medicação, inclusive a crianças que já estão medicadas. Dessa forma, se supostamente por tomar a Ritalina, a criança deveria produzir e se concentrar mais como defende a professora, por que essa mesma professora o encaminha para atendimento clínico justamente por não produzir e não se concentrar? Visto que a Ritalina contribui para que a criança produza na escola, como argumenta a própria escola, por que permanecem esses sinais de desatenção e desorganização? O que estaria acontecendo nesse caso? Diante de tais contradições, é importante questionar: qual a implicação da professora na escolarização dessas crianças?

Nesse sentido, cabe ressaltar que se está de acordo com Sibemberg (2013): não se está dizendo que os psicotrópicos nunca devam ser prescritos a crianças. Afinal, assumir uma postura nessa linha é igualmente reduzir o sujeito, mas, nesse caso, ao aspecto estritamente subjetivo, desconsiderando o seu aspecto orgânico. Porém, a crítica que se faz é em relação ao excesso de prescrições medicamentosas, como também à ausência de um estabelecimento de cunho científico quanto aos riscos e benefícios de medicações administradas em crianças e adolescentes, mas que até então eram prescritos somente à população adulta.

Enfim, diante desses recortes da prática clínica e escolar, pode-se depreender sobre a existência de repercussões relevantes quando se trata dos diagnósticos na infância. Isso configura, dessa forma, um desafio à clínica, pois demanda que a intervenção do profissional viabilize o desdobramento das questões que são provocadas em função desse ato precoce, possibilitando uma re-significação, após essa classificação psicopatológica que lhe é conferida, do lugar da criança frente à família e aos contextos por onde circula.

\section{CONSIDERAÇÕES FINAIS}

Após a discussão construída até este ponto, fundamentada na revisão teórica e nos comentários advindos da prática, pode-se dizer que a temática proposta nesse escrito caracteriza-se por ser inacabável. Nesse sentido, é possível relacioná-la ao caráter inconcluso que, a partir da psicanálise, assume um diagnóstico na infância, em função das peculiaridades desse período.

Dessa forma, ficam muitos questionamentos diante desse cenário decorrente da precocidade de um diagnóstico, assim como de suas consequências à criança, à 
sua constituição psíquica e ao seu desenvolvimento, à sua relação com as figuras parentais e com o social. Certamente, são interrogações que surgem não com o intuito de serem respondidas de prontidão, pelo contrário, nesse artigo não se buscou respostas ou soluções que dessem conta das perguntas, inicialmente e ao longo do trabalho, incitadas.

Nesse contexto, não por acaso procurou-se adotar indagações nos títulos dos capítulos que antecederam à articulação teórico-prática desse escrito, justamente por se acreditar que a clínica na infância e a hipótese diagnóstica decorrente dela devem ser conduzidas pelo profissional por meio de um caminho interrogativo. Em outras palavras, os títulos empregados buscaram representar uma necessária postura reflexiva e questionadora, não devendo o clínico estar engessado em verdades e afirmações absolutas.

No entanto, atualmente observa-se que a clínica psiquiátrica, numa perspectiva biologista, alicerça-se numa atuação nesse sentido, parecendo não se permitir armar interrogantes diante de um paciente, demonstrando não suportar o não-saber que o caso, muitas vezes, provoca. Ou seja, revela ser, em alguns momentos, uma clínica que não suporta lidar com a falta e, dessa forma, os manuais classificatórios vem ao encontro dessa questão, pois oferecem ao clínico praticamente todas as respostas possíveis.

Assim, considera-se que uma postura absolutista na clínica, independente de qual esfera se trata a atuação, mas especialmente quando se trata da prática com crianças, sujeitos em constituição, implica reduzi-las e aprisioná-las a um lugar que, por vezes, é irreversível. Dessa maneira, muitas dessas crianças passam a ser seus diagnósticos, e não a tê-los, como também a depender dos seus medicamentos como se fossem recursos imprescindíveis à sua sobrevivência. Diante disso, é relevante interrogar: onde está o desejo dessa criança? Ou melhor, ele existe? Há condições para que se constitua um sujeito desejante?

Nesse caminho, outras questões são extremamente importantes de serem levantadas. Considerando-se a crescente prescrição medicamentosa na infância como, muitas vezes, único recurso terapêutico preceituado, interroga-se: a serviço de que poderia estar esse fenômeno contemporâneo?

Ao discorrer especificamente sobre o aumento, nos últimos anos, de diagnósticos de TDAH em crianças, Tallis (2006) indaga sobre o porquê desse crescimento excessivo. Há, por um lado, a medicina, que tende a bi- ologizar os transtornos psíquicos e, por outro, a escola, que pende a patologizar todas as manifestações dos alunos que, para os professores, desviam-se daquilo que eles esperam que seja apresentado. Assim, se antigamente os que não se portavam bem eram encaminhados ao psicólogo, na atualidade são encaminhados, prioritariamente, ao neurologista, dado que uma pílula supostamente pode solucionar o problema. Nesse sentido, o autor ressalta que, nessa mudança, deve-se levar em conta a existência de uma tênue pressão da indústria farmacêutica para comercializar seus produtos lançados.

Dessa forma, faz-se fundamental refletir sobre o lugar que é oferecido à infância nesses contextos que a perpassam. E, além disso, no exercício da clínica, guiar-se e embasar-se junto aos questionamentos que advém dessas questões: que efeitos possíveis pode haver a esse sujeito em constituição, que é diagnosticado e medicado precocemente? Ainda, quais as possíveis repercussões no discurso escolar e social sobre essa criança?

Enfim, isso aponta para uma necessária e impreterível comunicação entre os campos de saber que se ocupam de estudar e tratar desse sujeito ainda em constituição. Afinal, a ausência - ou a carência - dessa articulação, que é substancial, indica a existência de uma irreal separação entre o orgânico e o psíquico.

\section{REFERÊNCIAS}

Adelino, C. M. (2010). Diagnóstico na infância: alguma conclusão possível? Psicologia Revista, 19(1), 79-96.

American Psychiatric Association (APA) (2014). Manual de Diagnóstico e Estatística de Distúrbios Mentais - DSM-5 ( $5^{\text {a }}$. ed.). Porto Alegre, RS: Artmed.

Angell, M. (2011). A epidemia de doença mental. Revista Piauí, 5, 45-49.

Brasil (2011). Decreto No 7.611, de 17de novembro de 2011. Dispõe sobre a educação especial, o atendimento educacional especializado e dá outras providências. Brasília, DF.

Brasil (2012). Agência nacional de vigilância sanitária (ANVISA). Boletim de Farmacoepidemiologia, 2(2), 1-14.

Bernardino, L. M. F. (2004). A intervenção psicanalítica nas psicoses não decididas na infância. In Colóquio do LEPSI IP/FE-USP, 5, São Paulo. Anais (p. 5). Retirado de http://www.proceedings.scielo.br/scie-

lo.php?pid=MSC0000000032004000100004\&script=sci_ arttext.

Bernardino, L. M. F. (2006). A abordagem psicanalítica do desenvolvimento infantil e suas vicissitudes. In L. M. F. Bernardino (Org.). O que a psicanálise pode ensinar sobre a criança, sujeito em constituição (pp. 19-41). São Paulo: Escuta.

Burkle, T. da S. (2009). Uma reflexão crítica sobre as edi- 
ções do manual de diagnóstico e estatística das perturbações mentais - DSM (Dissertação de Mestrado). Universidade Federal do Rio de Janeiro (UFRJ), Rio de Janeiro.

Bursztyn, D. C., \& Figueiredo, A. C. (2012). O tratamento do sintoma e a construção do caso na prática coletiva em saúde mental. Tempo psicanalítico, 44(1), 131-145.

Consultório etimológico (2013). Origem da palavra diagnóstico. Site de etimologia. Retirado de http://origemdapalavra.com.br/pergunta/pergunta-1191/

Coutinho, A. H. S. de A. (2007). Escutar é preciso, diagnosticar não é preciso. Reverso, 29(54), 99-108.

Dor, J. (1994). Estruturas e Clínica Psicanalítica. Rio de Janeiro: Taurus Editora.

Ferreira, A. B. de H. (2004). Novo dicionário Aurélio da língua portuguesa. (3. ed). Curitiba: Positivo.

Figueiredo, A. C., \& Tenório, F. (2002). O diagnóstico em psiquiatria e psicanálise. Revista Latinoamericana de Psicopatologia Fundamental, 1, 29-43.

Fiore, M. de A. (2005). Medicalização do Corpo na Infância. Mnemosine, 1(1), 364-380.

Freud, S. A Psicoterapia da Histeria (2006). In Breuer, J., \& Freud, S. Estudos sobre a Histeria [1895a]. Edição standard brasileira das obras psicológicas completas (Vol. II, pp. 271-316). Rio de Janeiro: Imago. (Trabalho original publicado em 1895).

Gellis, A. (2000). Diagnósticos e psicotrópicos - uma resposta pela psicanálise. Psicologia USP, 11(1), 107-118.

Guarido, R. (2007). A medicalização do sofrimento psíquico. Educação e Pesquisa, 33(1), 151-161.

Jerusalinsky, A. (2011). Gotinhas e comprimidos para crianças sem história. Uma psicopatologia pós-moderna para a infância. In A. Jerusalinsky \& S. Fendrik. O livro negro da psicopatologia contemporânea (pp. 231-242) São Paulo: Via Lettera.

Jerusalinsky, A (2013). Editorial. In Associação Psicanalítica de Porto Alegre - APPOA. Correio da APPOA. Dar a palavra aos autistas (pp. 1-3), 222/223, Porto Alegre.

Jerusalinsky, A., \& Coriat, E. (1996). Aspectos estruturais e instrumentais. In Centro Lydia Coriat, Escritos da Criança (pp. 7-13), 4, Porto Alegre.

Jerusalinsky, J. (2002). Enquanto o futuro não vem. A psicanálise na clínica interdisciplinar com bebês. Salvador: Editora Ágalma.

Jerusalinsky, J., Associação Psicanalítica de Porto Alegre, Centro Lydia Coriat, Clínica Interdisciplinar Mauro Spinelli, Lisondo, A., Freire, A. B., ... Pimenta, P. (2013). Autismos e seus tratamentos: contribuições da metodologia psicanalítica nesse campo. In Associação Psicanalítica de Porto Alegre - APPOA. Correio da APPOA. Dar a palavra aos autistas (pp. 25-45), 222/223, Porto Alegre.
Marcelli, D., \& Cohen, D. (2010). Infância e psicopatologia. Porto Alegre: Artmed.

Meira, A. M. G. (1998). Algumas considerações a respeito do diagnóstico de autismo na infância. In Centro Lydia Coriat, Escritos da criança (pp. 73-78), 5, Porto Alegre.

Mendonça, L. F. R. (2013). Reflexões sobre o diagnóstico como representação (Dissertação de Mestrado). Pontifícia Universidade Católica de São Paulo (PUCSP), São Paulo.

Mendonça, L. F. R., \& Berlinck, M. (2012). Diagnóstico: um sintoma? In V Congresso internacional de psicopatologia fundamental e XI Congresso brasileiro de psicopatologia fundamental, Anais, Fortaleza.

Organização Mundial da Saúde (OMS) (1993). Classificação de transtornos mentais e de comportamento da CID-10: Descrições clínicas e diretrizes. Porto Alegre, RS: Artes Médicas.

Petri, R. (2008). Psicanálise e infância: clínica com crianças. Rio de Janeiro: Cia de Freud.

Reis, C. do A. de M. (2000). Uma reflexão acerca do diagnóstico de psicose infantil: uma abordagem psicanalítica. Psicologia USP, 11(1), 207-242.

Romaro, R. A. (1999). O estabelecimento do diagnóstico em psicanálise. Revista PsicoUSF, 3(2), 23-27.

Sibemberg, N. (2013). Autismo: uma síndrome, diferentes abordagens. In Associação Psicanalítica de Porto Alegre APPOA. Correio da APPOA. Dar a palavra aos autistas (pp. 85-92), 222/223, Porto Alegre.

Tallis, J. (2006). Sobre o diagnóstico diferencial do transtorno por déficit de atenção. In Associação Psicanalítica de Porto Alegre - APPOA. Correio da APPOA. Diagnósticos na infância hoje (pp. 54-62), 144, Porto Alegre.

Vorcaro, A. (2011). O efeito bumerangue da classificação psicopatológica da infância. In A. Jerusalinsky \& S. Fendrik. O livro negro da psicopatologia contemporânea (pp.219-229). São Paulo: Via Lettera.

Recebido em: 21/10/2013 Primeira decisão editorial em: 07/03/2015 Aceito em: 23/01/2016

\section{Nota:}

1

Os recortes clínicos referenciados nesse trabalho são de casos atendidos pela equipe do serviço público ao qual a autora principal está vinculada. Ressalta-se que se obteve autorização do paciente e/ou de um dos seus responsáveis. 